\title{
Positive-ion thermospray liquid chromatography-mass spectrometry: detection of organic acidurias
}

\author{
DOUGLAS N. BUCHANAN*, JOSEPH MUENZER and JESS G THOENE
}

Department of Peduatmcs, Division of Biochemical Genetscs and Metabolsm, The University of Michigan, Ann Arbor, MI 48109 (U S A.)

(First received May 16th, 1990; revised manuscript received August 30th, 1990)

\begin{abstract}
Positive-ion thermospray liquid chromatography-mass spectrometry (TSP-LC-MS) is used to detect organic acids va the direct injection of untreated urine from newborns and infants. Two methods are reported for the separation of organic acids The separation of unnary organic acids is effected in either an acidic, $\mathrm{pH} 2.5$ sulfuric acıd, or a non-acidic, $005 \mathrm{M}$ ammonıum acetate, $\mathrm{pH} 6.8$, mobile phase. Use of $\mathrm{pH}$ 2.5 sulfuric acid and an HPX- $87 \mathrm{H}$ organic acid column produces better separation but has less sensit1vity than the use of $0.05 \mathrm{M}$ ammonum acetate, $\mathrm{pH} 6.8$ and a $\mathrm{C}_{18}$ column Positive 1on TSP-LC-MS has been used to detect methylmalonic aciduria, 3-hydroxy-3-methylglutaric acıduna, propionic aciduria, isovaleric aciduria and arginınosuccinic acıdurı
\end{abstract}

\section{INTRODUCTION}

The diret analysis of untreated urne by high-performance liquid chromatography (HPLC) using an organic acid column with a $\mathrm{pH} 2.5$ sulfuric acid mobile phase and an ultraviolet $[1,2]$ or a photodiode array detector [3-5] has proven to be a fast and effective way to detect organic acidurias in newborns and infants. There is no sample preparation and peak identification is based upon either retention time, retention time and wavelength ratio, or the characteristic ultraviolet spectrum. However, these methods do not provide unambiguous peak identifcation. Mass spectrometric analysis of an HPLC effluent facilitates peak ident1fication and enhances detection of organic acidurias. Mills et al. [6] have reported the detection of methylmalonic acid in the urine of a patient with methylmalonic aciduria using negative-ion plasmaspray LC-MS. In that study, the urine was directly injected onto an HPX-87H organic acid column with a $\mathrm{pH} 2.5$ formic acid mobile phase.

We now report the use of positive-ion thermospray LC-MS (TSP-LC-MS) for the detection of organic acidurias. The system employs the direet injection of 
urine onto either an HPX-87H organic acid column with a $\mathrm{pH} 25$ sulfuric acid mobile phase or a $5-\mu \mathrm{m} \mathrm{C}_{18}$ column with a $0.05 \mathrm{M}$ ammonium acetate, $\mathrm{pH} 6.8$ mobile phase

EXPERIMENTAL

\section{Chermicals}

All reagent chemicals and organic acid standards were from Sigma (St. Louis, MO, U.S.A ) and were used as recenved. HPLC water was from J. T. Baker (Phillipsburg, NJ, U.S.A.) and was filtered and sparged with helium prior to use.

\section{Instruments}

An HP-1050 HPLC system was connected to an HP-5988 single quadrapole mass spectrometer by an HP thermospray interface (Hewlett Packard, Palo Alto, CA, U.S.A.). An HP-1000 computer with RTE-A software was used for data collection and analysis.

\section{Analysis of urine}

A $0.02-\mathrm{ml}$ aliquot of untreated urine was injected either onto an $\mathrm{HPX}-87 \mathrm{H}$ (sulfonated polystyrene-divinylbenzene) organic acid column with a $3-\mathrm{cm}$ HPX-87H guard column (Bio-Rad Labs, Richmond, CA, U.S.A.) with a pH 2.5 sulfuric acid mobile phase pumped at $0.8 \mathrm{ml} / \mathrm{min}$, or onto a $5-\mu \mathrm{m}, 22 \mathrm{~cm} \times 4.6$ $\mathrm{mm} \mathrm{I.D} \mathrm{C}_{18}$ column with a $3 \mathrm{~cm} \times 4.6 \mathrm{~mm}$ I.D guard column (Brownlee Labs., Santa Clara, CA, U.S.A.) with a $0.05 \mathrm{M}$ ammonium acetate, $\mathrm{pH} 6.8$ mobile phase pumped at $0.8 \mathrm{ml} / \mathrm{min}$. Both HPLC columns were maintaned at $30^{\circ} \mathrm{C}$ by a column heater (Bio-Rad Labs.) and were preceded by the appropriate guard column. The thermospray probe was maintained at $112^{\circ} \mathrm{C}$ and the mass spectrometer was at $276^{\circ} \mathrm{C}$. All analyses were run with the ionization filament on. A range of 105-365 a.m.u. was scanned for the total-ion-current (TIC) chromatogram. Extracted-ion profiling of ions extracted from the TIC was used for compound detection. The guard columns used permit at least 100 injections of untreated urine before they need to be replaced.

Sensitivity of TSP -LC-MS toward organic acids in $0.05 \mathrm{M}$ ammonium acetate, $p H$ 6.8

Organic acids at concentrations of $0.02-1.0 \mathrm{mg} / \mathrm{ml}$ were injected onto the $\mathrm{C}_{18}$ HPLC column. The TIC chromatogram and the extracted-ion chromatogram (using the base peak of the TSP mass spectrum as the ion monitored) were recorded. From these chromatograms, the limit of detection (signal $>3 \mathrm{X}$ noise) was between 50 and $500 \mu \mathrm{g} / \mathrm{ml}$ for TIC but for extracted-ion profiling was $5-50$ $\mu \mathrm{g} / \mathrm{ml}$ (see Table I) Thus, extracted-ion profiling of ions extracted from the TIC is five to ten times more sensitive than the 105-365 a.m.u. TIC under these conditions. 
TABLE I

DETECTION LIMITS FOR SOME ORGANIC ACIDS IN $005 M$ AMMONIUM ACETATE pH 68

\begin{tabular}{llrl}
\hline \multirow{2}{*}{$\begin{array}{l}\text { Retention time } \\
(\mathrm{min})\end{array}$} & \multicolumn{2}{l}{ Detection limit $(\mu \mathrm{g} / \mathrm{ml})$} \\
\cline { 3 - 4 } & & TIC & Extracted-ion profiling \\
\hline Citruc acid & 27 & 500 & 80 \\
Methylmalonic acid & 28 & 150 & 60 \\
3-Methylglutaric acid & 29 & 200 & 30 \\
3-Hydroxy-3-methylglutaric acid & 29 & 50 & 5 \\
Argininosuccmic acid & 3.0 & 160 & 25 \\
5-Oxoproline & 31 & 100 & 20 \\
4-Hydroxyphenyllactic acid & 63 & 100 & 20 \\
Isovalerylglycine & 113 & 50 & 5 \\
Hexanoylglycine & 450 & 50 & 5 \\
\hline
\end{tabular}

RESULTS AND DISCUSSION

Mills et al. [6] reported that organic acids are not very responsive toward negative-ion plasmaspray MS in $\mathrm{pH} 2.5$ formic acid. Using a $\mathrm{pH} 2.5$ sulfuric acid mobile phase, we found the same to be true for positive-ion TSP-LC-MS. We did observe a linear relationship between the $\mathrm{pH}$ of the mobile phase up to $\mathrm{pH} 6.8$ and the positive-ion TSP-MS response toward organic acids, oxocarboxylic acids and carbohydrates. The detector response is greater for carbohydrates and oxo-

\section{TABLE II}

RETENTION TIMES AND POSITIVE-ION TSP/MASS SPFCTRA OF SOME ORGANIC ACIDS IN $0.05 M$ AMMONIUM ACETATE pH 68

\begin{tabular}{lcrl}
\hline Compound & Retention lime (min) & MW & TSP mass spectrum \\
\hline 3-Hydroxy-3-methylglutaric acid & 26 & 162 & $163\left(\mathrm{M}+\mathrm{H}^{+}\right), 180\left(\mathrm{M}+\mathrm{NH}_{4}{ }^{+}\right)$ \\
3-Methylglutaconic acid & 26 & 144 & $162\left(\mathrm{M}+\mathrm{NH}_{4}^{+}\right)$ \\
3-Methylglutaric acid & 27 & 146 & $164\left(\mathrm{M}+\mathrm{NH}_{4}^{+}\right)$ \\
Methyicinc acid & 29 & 206 & $224\left(\mathrm{M}+\mathrm{NH}_{4}^{+}\right)$ \\
Arginnosuccinic acid & 3.0 & 290 & $256\left(\mathrm{M}+\mathrm{H}^{+}-\mathrm{H}_{2} \mathrm{O}_{-} \mathrm{NH}_{3}\right)$ \\
Urea & 33 & 60 & $121\left(2 \mathrm{M}+\mathrm{H}^{+}\right), 181\left(3 \mathrm{M}+\mathrm{H}^{+}\right)$ \\
Methylmalonic acid & 34 & 118 & $136\left(\mathrm{M}+\mathrm{NH}_{4}^{+}\right)$ \\
3-Hydroxyisovaleric acid & 43 & 118 & $119\left(\mathrm{M}+\mathrm{H}^{+}\right), 136\left(\mathrm{M}+\mathrm{NH}_{4}^{+}\right)$ \\
Creatinine & 53 & 113 & $114\left(\mathrm{M}+\mathrm{H}^{+}\right), 227\left(2 \mathrm{M}+\mathrm{H}^{+}\right)$ \\
Isovalerylglycine & 104 & 159 & $160\left(\mathrm{M}+\mathrm{H}^{+}\right), 177\left(\mathrm{M}+\mathrm{NH}_{4}^{+}\right)$ \\
Tiglylglycine & 146 & 157 & $158\left(\mathrm{M}+\mathrm{H}^{+}\right), 175\left(\mathrm{M}+\mathrm{NH}_{4}^{+}\right)$ \\
Hippuric acid & 270 & 179 & $180\left(\mathrm{M}+\mathrm{H}^{+}\right), 197\left(\mathrm{M}+\mathrm{NH}_{4}^{+}\right)$ \\
\hline
\end{tabular}


carboxylic acids than for carboxylic acids in the $\mathrm{pH}$ range from 2.5 to 6.8 . The HPX-87H organic acid column cannot be used to separate organic acids with a non-acidic pH 6.8 mobile phase. Therefore, a new method for the separation of organic acids by HPLC was required.

A $5-\mu \mathrm{m} 22 \mathrm{~cm} \times 4.6 \mathrm{~mm}$ I.D $\mathrm{C}_{18}$ HPLC column with an $0.05 \mathrm{M}$ ammonium acetate, $\mathrm{pH} 6.8$ mobile phase was used to produce separation of compounds (Table II) characteristic of some representative inborn errors of metabolism (Table III). In this mobile phase, these compounds were five to ten times more responsive to positive-ion TSP-MS than in $\mathrm{pH} 25$ sulfuric acid mobile phase. The detection limit for these compounds using positive-ion TSP-LC-MS in $0.05 \mathrm{M}$ ammonium acetate, $\mathrm{pH} 6.8$ is less than $100 \mu \mathrm{g} / \mathrm{ml}$ as shown in Table I. Gas chromatographic-mass spectrometric (GC-MS) analysis of the trimethylsilyl (TMS) derivative of these compounds, extracted form urine, has a detection limit of $1-5 \mu \mathrm{g} / \mathrm{ml}$ for TIC [7] and lower for extracted-ion profiling for ion extracted from the TIC.

The urine from a three day-old female infant born to first cousin parents of Middle East origin who lapsed into a coma with profound metabolic acidosis due to 3-hydroxy-3-methylglutaric aciduria was analyzed by both HPLC and TSPLC-MS. The UV chromatogram $(190 \mathrm{~nm})$ of the urine from this infant with 3-hydroxy-3-methylglutaric aciduria is shown in Fig 1A. For HPLC analysis, the urine was directly injected onto a dual-column system [1] with $\mathrm{pH} 2.5$ sulfuric acid as the mobile phase. The 17.4 min peak is uric acid and the $23.3 \mathrm{~min}$ peak is 3-methylglutaconic acid [4]. The positive-ion TSP-LC-MS chromatogram of this urine directly injected onto an HPX-87H organic acid column with a $\mathrm{pH} 2.5$ sulfuric acid mobile phase is shown in Fig. 1B. 3-Hydroxyisovaleric acid and 3-hydroxy-3-methylglutaric acid are observed in the chromatogram. The positive-ion TSP-LC-MS TIC chromatogram of this same urine directly injected

TABLE III

METABOLITES CHARACTERISTIC OF SOME INBORN ERRORS OF METABOLISM

\begin{tabular}{lll}
\hline Disease & Characteristic metabolite & TSP-LC-MS detection \\
\hline Methylmalonic aciduria & Methylmalonic acid & + \\
& Methylcitric acid & + \\
Proprionic aciduria & Methylcitric acid & + \\
& Tiglyglycine & - \\
& Propionylglycine & + \\
3-Hydroxy-3-methylglutaric aciduria & 3-Hydroxyisovaleric acid & + \\
& 3-Hydroxy-3-methylglutanc acid & + \\
& 3-Methylglutaconic acid & + \\
Isovaleric aciduria & 3-Methylglutaric acid & + \\
Argininosuccinic aciduria & Isovalerylglycine & + \\
\end{tabular}



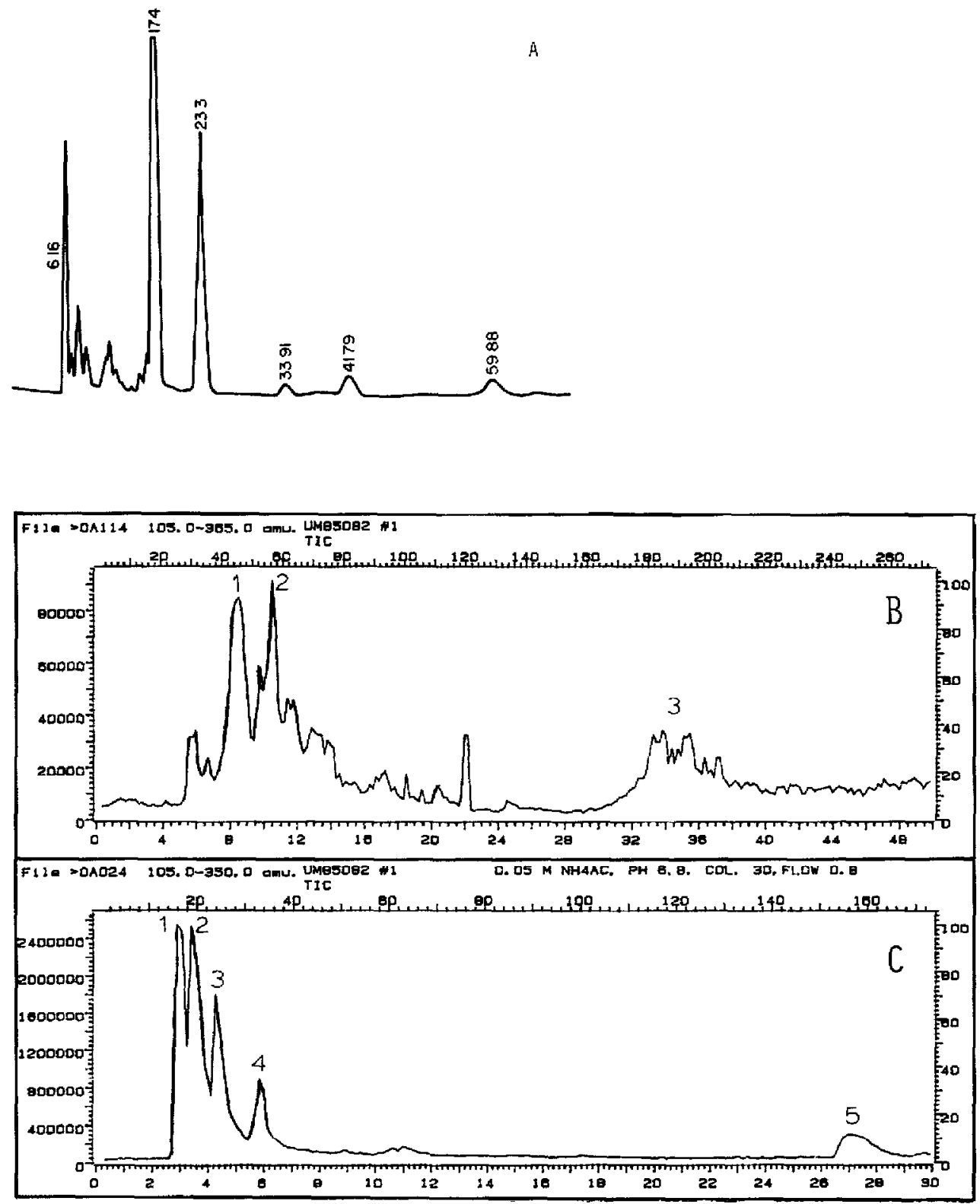

Fig 1 Analysis of the urine from a 3-hydroxy-3-methylglutanc acidura patient. (A) A 190-nm chromatogram using dual column HPLC [4] with $\mathrm{pH} 25$ sulfuric acid mobile phase at $08 \mathrm{ml} / \mathrm{m} / \mathrm{n}$. The peak at 17.4 min is uric acid and the peak at $23.3 \mathrm{~mm}$ is 3-methylglutaconic acid (published with permission from ref. 4) (B) Positive-1on TSP-LC-MS with an HPX-87H column with a $\mathrm{pH} 25$ sulfunc acid mobile phase at 0.8 $\mathrm{ml} /$ min Peak 1 contains 3-hydroxy-3-methylglutaric acid, peak 2 is 3-hydroxyısovaleric acid and peak 3 is urea. (C) Positive-ion TSP-LC-MS with a $\mathrm{C}_{18}$ column using a $0.05 \mathrm{M}$ ammonium acetate, pH 68 mobile phase at $08 \mathrm{ml} / \mathrm{min}$ Peak 1 contans 3-hydroxy-3-methylglutaric acid and 3-methylglutaconic acid, peak 2 is urea; peak 3 is 3-hydroxyısovaleric acid; peak 4 is creatinıne and peak 5 is hippuric acid. 


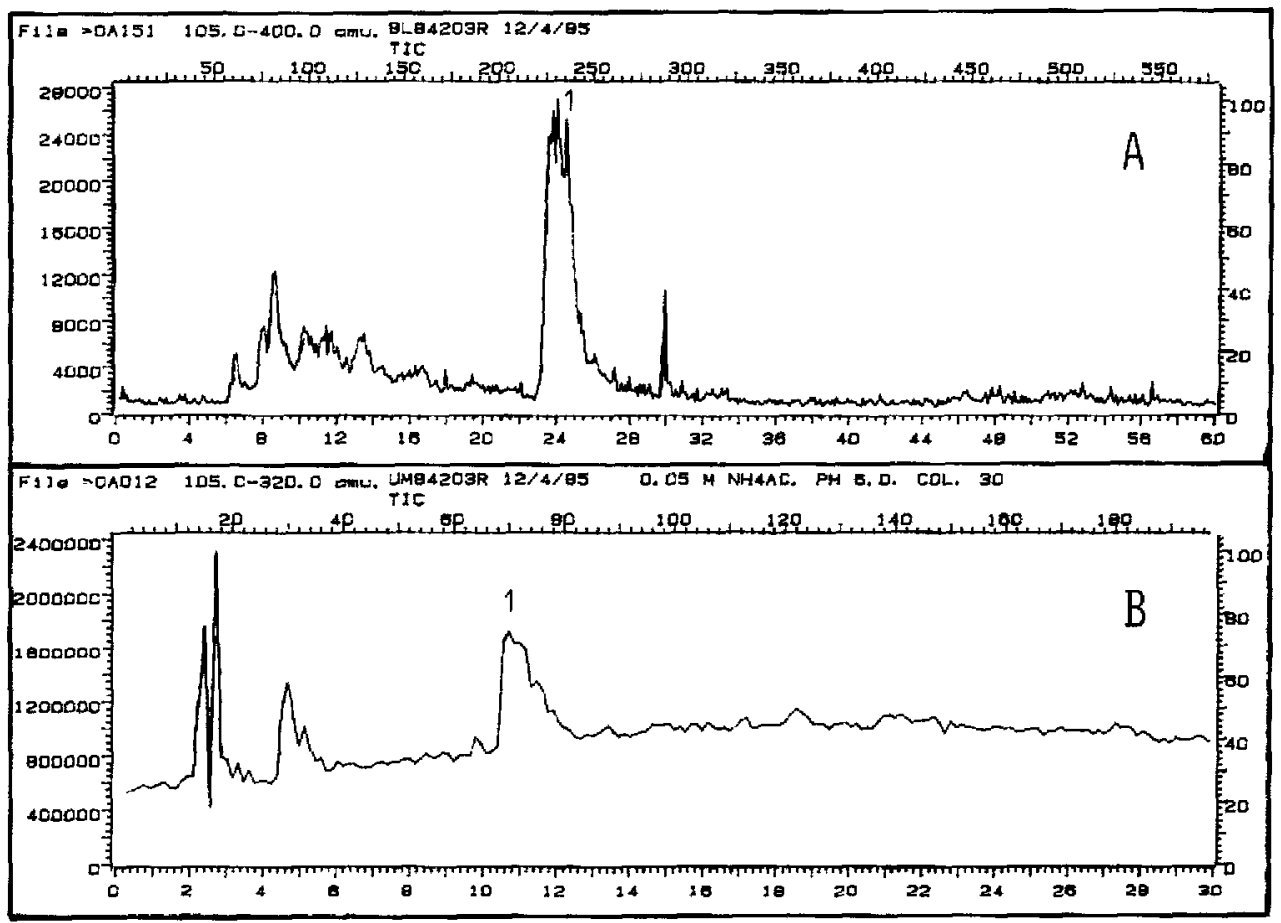

Fig 2. TSP-LC-MS analysis of the urine from an isovaleric aciduria patient. (A) HPX-87H column with a pH 2.5 sulfuric acid mobile phase at $08 \mathrm{ml} / \mathrm{min}$ Peak 1 is isovalerylglycine. (B) $\mathrm{C}_{18}$ column with a $0.05 \mathrm{M}$ ammonium acetate, $\mathrm{pH} 68 \mathrm{mobile}$ phase at $08 \mathrm{~mL} / \mathrm{min}$ Peak 1 is sovalerylglycine.

onto a $5-\mu \mathrm{m}, 22 \mathrm{~cm} \times 4.6 \mathrm{~mm}$ I.D. $\mathrm{C}_{18}$ column with an $0.05 M$ ammonium acetate, pH 6.8 mobile phase is shown in Fig. 1C. 3-Hydroxyisovaleric acid, 3-hydroxy-3-methylglutaric acid and 3-methylglutaconic acid are detected and identified directly from the TSP mass spectrum of the peak or through the use of selected-ion monitoring (peak 1 consists of 3-hydroxy-3-methylglutaric acld and 3-methylglutaconic acid). Note the difference in scale of the detector in Fig. 1B and $\mathrm{C}$.

The positive-ion TSP-LC-MS TIC chromatogram of the urine from a metabolically stable six-year-old female who has isovaleric aciduria is shown in Fig. 2. A large peak due to isovalerylglycine is observed in both solvent sytems.

The positive-1on TSP-LC-MS TIC chromatogram of the urine from a metabolically stable eight-year-old male who has propionic aciduria who was being treated with a $1.0 \mathrm{~g} / \mathrm{kg}$ per day protein restriction diet is shown in Fig. 3. Methylcitric acid and tiglylglycine are detected in both solvent systems.

A urine sample from a five-day-old female infant who presented with severe metabolic acidosis, lethargy, hypothermia and hyperammonemia was analyzed by TSP-LC-MS. The positive-1on TSP-LC-MS TIC chromatogram from this infant with methylmalonic aciduria is shown in Fig. 4. A large methylmalonic 


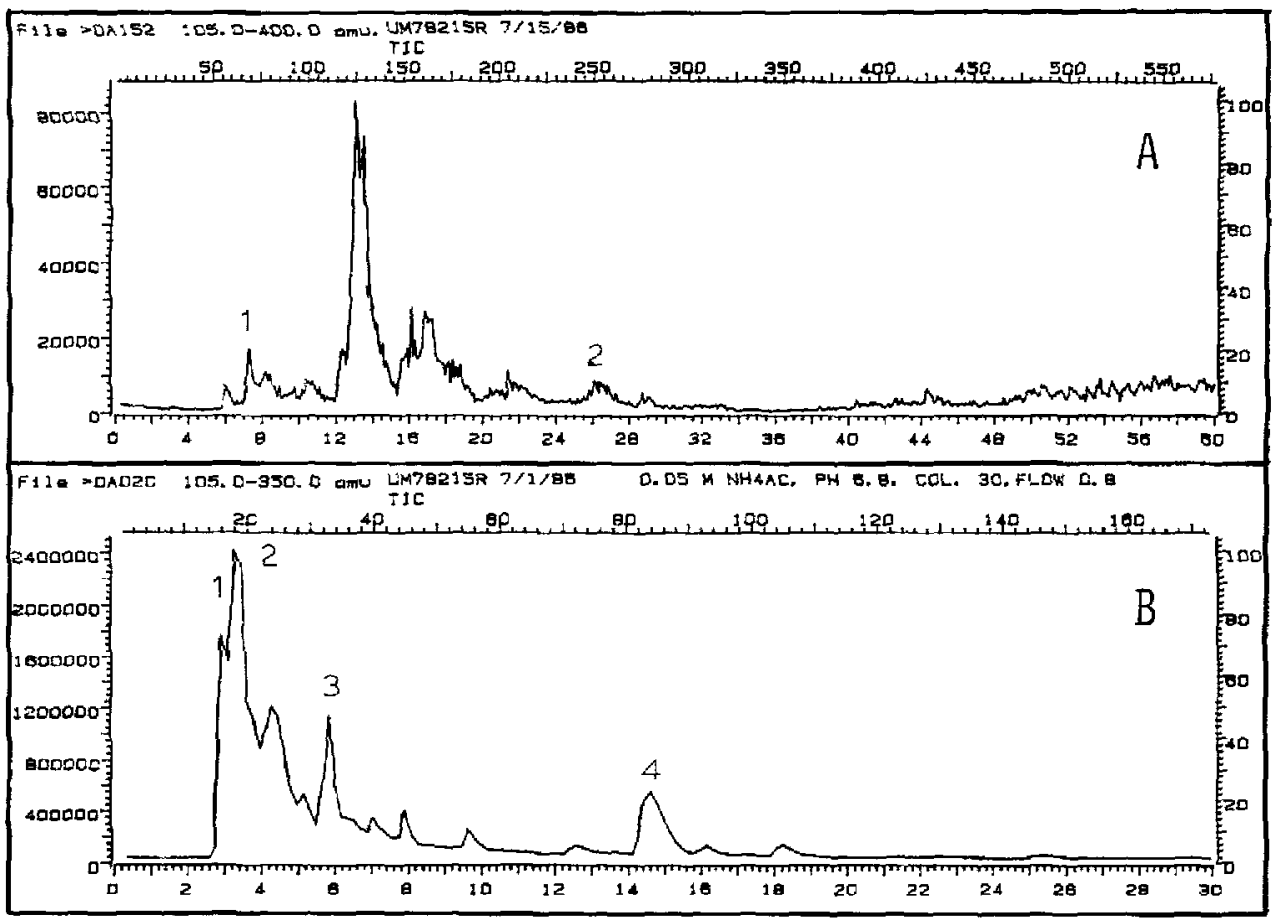

Fig 3 Positive-ion TSP-LC-MS analysis of the urine from a propionic acid aciduria patient. (A) HPX-87H column with a pH 2.5 sulfuric acld mobile phase at $08 \mathrm{ml} / \mathrm{mm}$; peak 1 is methylcitre acid and peak 2 is tiglylglycine (B) $C_{18}$ column with a $005 M$ ammonium acetate, $\mathrm{pH} 68$ moble phase at 08 $\mathrm{mI} / \mathrm{mın}$; pea $\bar{k} I$ is methylcitric acıd, peak 2 is urea, pea $\bar{k} 3$ is creatınıne and peak 4 is tıglyIglycine.

acid peak is observed in both solvent systems. In addition, methylcitric acid is seen in the ammonium acetate mobile phase (Fig. 4B).

The positive-ion TSP-LC-MS TIC chromatogram using $0.05 \mathrm{M}$ ammonium acetate as the mobile phase of the urine from a three-day-old female infant who has argininosuccinic aciduria is shown in Fig. 5A. The infant was hospitalized with a one-day history of poor feeding, lethargy progressing to coma and an ammonum of $1170 \mu \mathrm{mol} / 1$ (normal $<35 \mu \mathrm{mol} / \mathrm{l}$ ) The mobile phase used, $\mathrm{pH} 2.5$ sulfuric acid, would protonate argininosuccinic acid and make it incompatible with an HPX-87H organic acid column. Fig. 5B shows the extracted $m / z 256$ selected-ion monitoring profile of argininosuccinic acid; $m / z 256$ represents a loss of water and ammonia from the protonated molecule $\left(\mathrm{M}+\mathrm{H}^{+}-\mathrm{H}_{2} \mathrm{O}-\mathrm{NH}_{3}\right)$.

Extracted-ion profiling of ions extracted from the TIC may be used to increase the sensitivity of the method and to facilitate identification of co-eluting compounds. The ions extracted from the TIC should represent the base peak in the positive-ion TSP mass spectrum of each compound (Table II and IV).

At $\mathrm{pH} 2.5$, the amino moiety of an amino acid is protonated, thus preventing 


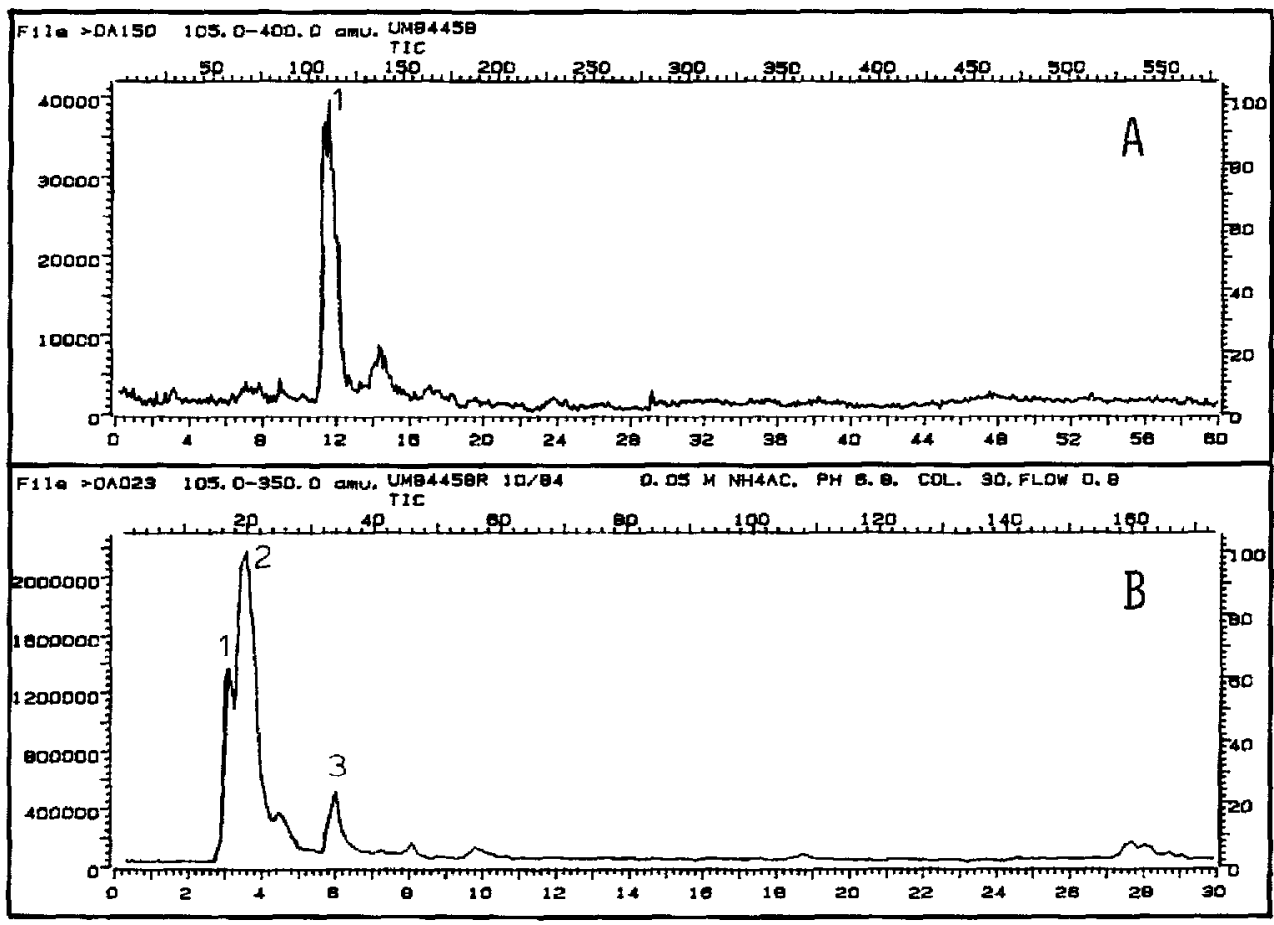

Fig. 4. Positive-ion TSP-LS-MS analysis of the urine from a methylmalonic aciduria patient (A) HPX-87H column with a pH 25 sulfuric acid mobile phase at $0.8 \mathrm{ml} / \mathrm{min}$, the peak at 7.0 is methylctric acid and peak 1 is methylmalonic acid (B) $\mathrm{C}_{18}$ column with a $0.05 \mathrm{M}$ ammonium acetate, $\mathrm{pH} 6.8$ mobile phase at $0.8 \mathrm{ml} / \mathrm{mmn}$, peak 1 is methylcitric acid, peak 2 is methylmalonic acid and urea and peak 3 is creatunine.

the amino acid from traversing the HPX-87H organic acid column. Amino acids, however, do traverse the $\mathrm{C}_{18}$ column in the ammonium acetate mobile phase and are detectable by positive-ion TSP-MS.

Urea is a major component of urine and is detected in the positive-1on TSPLC-MS profile by both methods. In the sulfuric acid mobile phase on an HPX-87H column, urea elutes well after the compounds of metabolic importance (Table IV). In the ammonium acetate mobile phase on a $\mathrm{C}_{18}$ column, urea elutes early in the chromatogram and may obscure some compounds of metabolic interest (Table II). The TSP mass spectrum of urea is the same in both mobile phases and consists chiefly of the protonated hydrogen bonded $\operatorname{dimer}\left(2 \mathrm{M}+\mathrm{H}^{+}\right)$ and a small amount of the protonated hydrogen bonded trimer $\left(3 \mathrm{M}+\mathrm{H}^{+}\right)$. Monomeric urea $(M=60)$ may be present but is not observed in scans from 105 to 365 a.m.u.

The positive-ion TSP mass spectrum of organic acids in the sulfuric acid mobile phase consists of the protonation of the molecule $\left(\mathrm{M}+\mathrm{H}^{+}\right)$, the addition of 


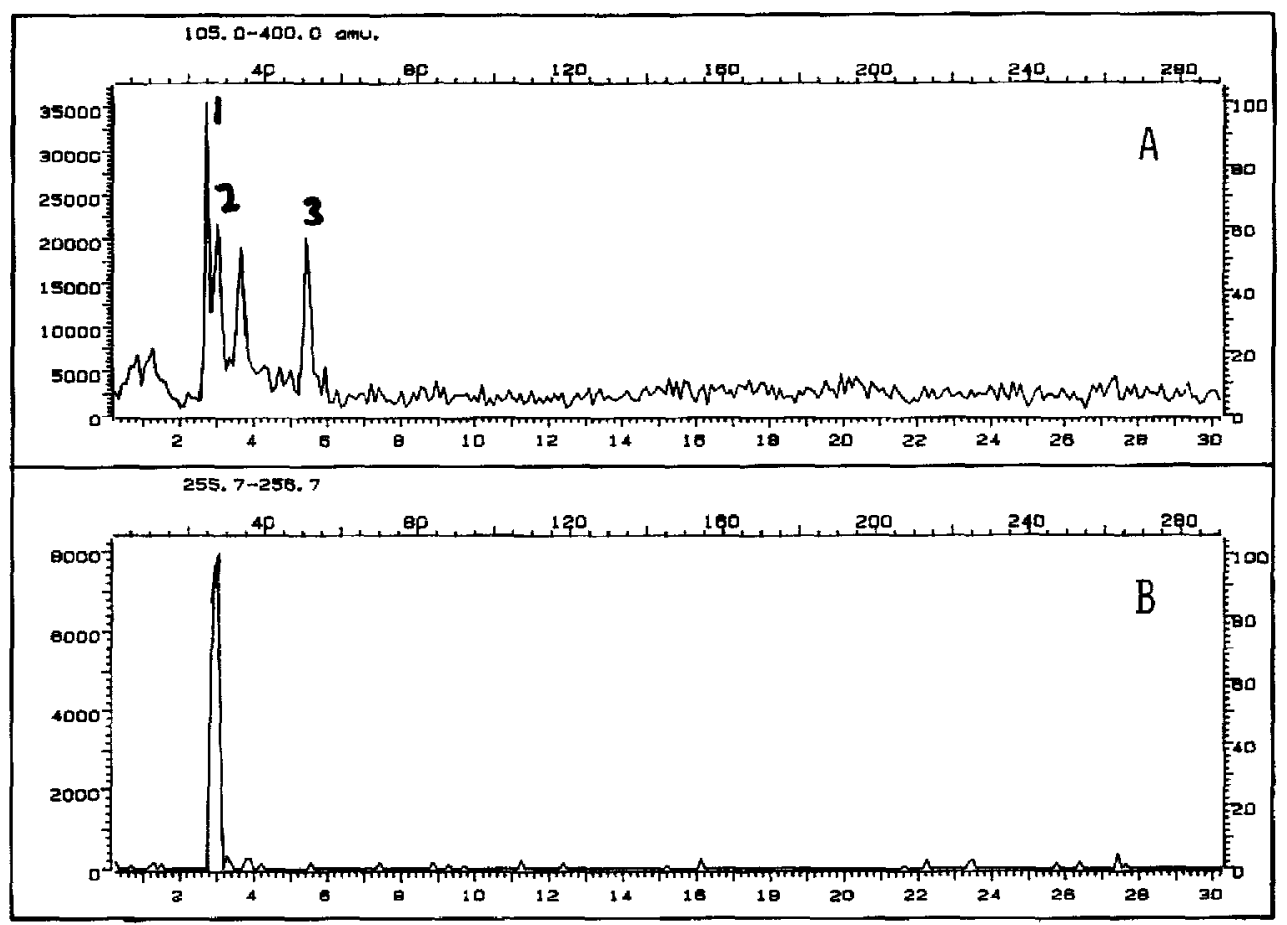

Fig. 5. (A) Positive-1on TSP-LC-MS analysis of the urine from an argminosuccinic aciduria patient using a $\mathrm{C}_{18}$ column and a $0.05 \mathrm{M}$ ammonium acetate, $\mathrm{pH} 6.8$ mobile phase Peak 1 is urea, peak 2 is arginınosuccinic acid and peak 3 is creatinine. (B) Exiracted-ıon protile, $m / z 256$, to indicate the presence of arginnosuccinic acid.

TABLE IV

RETENTION TIMES AND TSP MASS SPECTRA OF SOME ORGANIC ACIDS IN THE pH 25 SULFURIC ACID MOBILE PHASE

Compound

Methylcitric acid

3-Hydroxy-3-methylglutaric acid

Methylmalonic acid

3-Hydroxy1sovaleric acid

Trglylglycine

3-Methylglutaric acid

3-Methylglutaconic acid

Isovalerylglycine

Urea

Hippuric acid

\section{Retention time \\ MW TSP mass spectrum}

(min)

\section{3}

10.6

114

135

14.0

15.5

16.8

238

31.0

479
$206207\left(\mathrm{M}+\mathrm{H}^{+}\right), 225\left(\mathrm{M}+\mathrm{H}_{3} \mathrm{O}^{+}\right)$

$162127\left(\mathrm{M}+\mathrm{H}^{+}-2 \mathrm{H}_{2} \mathrm{O}\right), 145\left(\mathrm{M}+\mathrm{H}^{+}-\mathrm{H}_{2} \mathrm{O}\right)$, $163\left(\mathrm{M}+\mathrm{H}^{+}\right), 181\left(\mathrm{M}+\mathrm{H}_{3} \mathrm{O}^{+}\right)$

$118 \mathrm{I} 19\left(\mathrm{M}+\mathrm{H}^{+}\right), 137\left(\mathrm{M}+\mathrm{H}_{3} \mathrm{O}^{+}\right)$, $237\left(2 \mathrm{M}+\mathrm{H}^{+}\right)$

$118119\left(\mathrm{M}+\mathrm{H}^{+}\right), 137\left(\mathrm{M}+\mathrm{H}_{3} \mathrm{O}^{+}\right)$, $237\left(2 \mathrm{M}+\mathbf{H}^{+}\right)$

$157 \quad 158\left(\mathrm{M}+\mathrm{H}^{+}\right), 176\left(\mathrm{M}+\mathrm{H}_{3} \mathrm{O}^{+}\right)$

$146147\left(\mathrm{M}+\mathrm{H}^{+}\right), 165\left(\mathrm{M}+\mathrm{H}_{3} \mathrm{O}^{+}\right)$

$144127\left(\mathrm{M}+\mathrm{H}^{+}-\mathrm{H}_{2} \mathrm{O}\right), 145\left(\mathrm{M}+\mathrm{H}^{+}\right)$, $163\left(\mathrm{M}+\mathrm{H}_{3} \mathrm{O}^{+}\right)$

$159160\left(\mathrm{M}+\mathrm{H}^{+}\right), 178\left(\mathrm{M}+\mathrm{HI}_{3} \mathrm{O}^{+}\right)$

$60121\left(2 \mathrm{M}+\mathrm{H}^{+}\right), 181\left(3 \mathrm{M}+\mathrm{H}^{+}\right)$

$179180\left(\mathrm{M}+\mathrm{H}^{+}\right), 198\left(\mathrm{M}+\mathrm{H}_{3} \mathrm{O}^{+}\right)$ 
the hydronium ion to the molecule $\left(\mathrm{M}+\mathrm{H}_{3} \mathrm{O}^{+}\right)$and an additional small amount of ions derived from protonation of the hydrogen bonded dimer $\left(2 \mathrm{M}+\mathrm{H}^{+}\right)$. Oxocarboxylic acids and carbohydrates also produce ions from the loss of one or more water molecules from the protonated molecule $\left(\mathrm{M}+\mathrm{H}^{+}-x \mathrm{H}_{2} \mathrm{O}\right)$. Examples are shown in Table IV. In contrast, using $0.05 \mathrm{M}$ ammonium acetate, $\mathrm{pH} 6.8$, the positive-ion TSP mass spectrum of organic acids is dominated by the protonated molecule $\left(\mathrm{M}+\mathrm{H}^{+}\right)$and by the addition of the ammonium ion to the molecule $\left(\mathrm{M}+\mathrm{NH}_{4}{ }^{+}\right)$. Polycarboxylic acids such as methylcitric acid and dicarboxylic acids such as methylmalonic acid do not produce significant protonated molccular ion peaks $\left(\mathrm{M}+\mathrm{H}^{+}\right)$but do produce $\mathrm{M}+\mathrm{NH}_{4}{ }^{+}$peaks as the base peak in their positive-ion TSP mass spectrum. Creatinine and 5-oxoproline form the protonated monomer $\left(\mathrm{M}+\mathrm{H}^{+}\right)$and the protonated dimer $\left(2 \mathrm{M}+\mathrm{H}^{+}\right)$in addition to a $\left(\mathrm{M}+\mathrm{NH}_{4}^{+}\right)$peak in their positive-1on ISP mass spectrum. Oxocarboxylic acids and carbohydrates produce $\mathrm{M}+\mathrm{NH}_{4}{ }^{+}$and $\mathrm{M}+\mathrm{NH}_{4}{ }^{+}-\mathrm{H}_{2} \mathrm{O}$ peaks [8]. Very little $\mathbf{M}+\mathrm{H}^{+}$is formed in the positive-ion TSP mass spectrum of these compounds (Table II)

Oxo compounds were much more responsive toward positıve-1on TSP-MS than non-oxo compounds in both mobile phases. Compounds such as uric acid and orotic acid (6-carboxyuracil) were not detected by positive-ion TSP-MS in either mobile phase.

Mills et al. [6] did not report the detection of carbohydrates in the negative-ion plasmaspray $\mathrm{LC}-\mathrm{MS}$ analysis of urine using $\mathrm{pH} 2.5$ formic acid and an $\mathrm{HPX}-87 \mathrm{H}$ organic acid column. We were able to detect urinary carbohydrate in the positiveIon TSP-LC-MS profiles in either mobile phase, but there was little separation of these monosaccharides. Glucose, galactose and fructose co-elute and ribose and xylose co-elute on either the HPX-87H or the $C_{18}$ column. Thus, this system appears to have limited usefulness in the diagnosis of disorders of carbohydrate metabolism.

Major technological advances have resulted in continued improvement in the diagnosis and care of infants born with inborn errors of metabolism. Disorders of organic acid metabolism result from defects in the oxidation of the carbon skeleton of ammo acids after transamination. Detection of these extracted organic acids has relied upon GC-MS analysis of their TMS derivative. Since rapid diagnosis is crucial to a good clinical outcome, we have emphasized methods with little or no sample preparation. The combination of MS with the resolving capacity of HPLC affords an optimal system for such analyses.

\section{ACKNOWLEDGEMENT}

This research was supported in part by a grant from the Michigan Department of Mental Health Biochemical Genetics Screening Program. 


\section{REFERENCES}

D. N Buchanan did J. G. Thoene, Anal. Biochem, 124 (1982) 108

2 M. J Bennett and C. E Brady, Clin. Chem., 30 (1984) 542

3 D N. Buchanan and J G Thoene, J. Chromatogr., 344 (1985) 23

4 D N Buchanan and J G Thoene, Clm Chem, 32 (1986) 169

5 D. N. Buchanan and J G. Thoene, Blomed. Chromatogr., I (1986) 38

6 G. A. Milss, V. Walker, M R. Clench and V C Parr, Bromed Envron., Mass Spectrom., 16(1988) 259

7 R. A. Chalmers, M. J. R. Healy, A. M. Lawson, J T. Hart and R W E Watts, Clin Chem, 22 (1976) 1292

8 N V. Esterban, D J. Linerato, J B Sidbury and A. L. Yergey, Anal Chem, 59 (1987) 1674. 